\title{
PAULO FREIRE - O ANÚNCIO DA ESPERANÇA
}

\author{
PAULO FREIRE - THE ANNOUNCEMENT OF HOPE
}

\author{
iD Dulce Consuelo Andreatta Whitaker \\ Professora Emérita \\ Universidade Estadual Paulista - UNESP. \\ Araraquara, SP - Brasil. \\ sil.onofre@uol.com.br \\ Diego da Costa Vitorino \\ Doutor \\ Universidade de São Paulo - USP/Diversitas. \\ São Paulo, SP - Brasil. \\ diego.vitorino82@gmail.com \\ Elis Cristina Fiamengue \\ Doutora \\ Universidade Estadual de Santa Cruz - UESC. \\ Ilhéus, Bahia - Brasil. \\ eliscf@gmail.com
}

Resumo: O olhar peculiar que lançamos nesse artigo para abordar a trajetória intelectual do patrono da educação brasileira nos instigou a compreender esse grande autor multifacetado também por sua face mais esperançosa, como uma forma de alento e contraponto ao avanço da onda neoconservadora. Analisamos Paulo Freire por alguns ângulos: a influência das mulheres em sua vida, os momentos de seu pensamento e os contextos sociais que o ajudaram a forjar o próprio fazer científico, além de observá-lo pelo viés das perseguições, do conservadorismo e do autoritarismo na sociedade brasileira de ontem e hoje. Apesar do avanço da onda neoconservadora, nosso patrono ainda tem nos ensinado que a educação pode deixar de ser reprodutora e passar a ser libertadora, sendo utilizada como uma tecnologia social importante para o despertar da autonomia, ao invés da opressão, e o incentivo a formas de ação social libertadoras e humanizadoras, ou seja, não opressoras. A obra de Freire é um prenúncio de esperança.

Palavras-Chave: educação libertadora; educação reprodutora; esperança. Neoconservadorismo; trajetória intelectual de Freire.

Abstract: In this article, we discuss the intellectual work of the Brazilian patron of education. The peculiar look towards this great and multifaceted author has helped us to understand him better. What is more, his hopeful side has also contributed to a better understanding of his thoughts. This points to an encouragement and counterpoint form against the advance of neoconservative wave in Brazil. In this way, we have analyzed Paulo Freire by some perspectives such: women influence in his life, his thinking reflections, and the social contexts that helped him elaborate his scientific practice. Besides, he has been studied by the persecution bias, conservatism, and authoritarianism in Brazilian society, from the past to nowadays. Despite the advance of the ultraconservative wave, we have learned from our patron that education must not be seen as a reproductive process but as a liberating one. In this sense, it should be faced as an important social technology to promote autonomy, not oppression, and to encourage humanizing and liberating forms of social action. Freire's work is a foreshadowing of hope.

Keywords: liberating education; reproductive education; hope; neoconservatism; Freire's intellectual trajectory.

Para citar - (ABNT NBR 6023:2018)

WHITAKER, Dulce Consuelo Andreatta; VITORINO, Diego da Costa; FIAMENGUE, Elis Cristina. Paulo Freire - o anúncio da esperança. Eccos - Revista Científica, São Paulo, n. 58, p. 1-19, e14610, jul./set. 2021. Disponível em: https://doi.org/10.5585/eccos.n58.14610. 


\section{Introdução}

A originalidade do pensamento de Freire nem sempre é percebida. Pensar "freirianamente" não é fácil. Talvez por isso seus métodos e suas ideias sejam mais comentados e elogiados do que propriamente aplicados.

Dois professores publicaram artigo no Le Monde Diplomatique, afirmando que Freire nunca foi aplicado nas escolas brasileiras (FAGUNDES \& BARBOSA, 2019). Apesar do evidente exagero da afirmação - afinal há experiências com base nas teorias e método propostos por Freire - o fato é que a maioria da escolaridade de nossas crianças e adolescentes passa ao largo da profundidade exigida para a compreensão do seu pensamento.

Então vejamos: Freire foi ao mesmo tempo revolucionário e pacifista, ou melhor, foi um ser pacífico. O aparente paradoxo se explica pelo caráter amoroso do seu discurso epistemológico. Ser revolucionário e pacificador é uma contradição no plano semântico. Mas é uma contradição que ocorre no plano factual. Para prová-lo, basta que contemplemos a História e lembremos, por exemplo, Gandhi, Martin Luther King ou Gramsci e um grande marxista que acreditou na revolução através da escolarização. Estamos falando de Raymond Williams em The Long Revolution ${ }^{1}$.

No Brasil, Freire não é reconhecido por suas ideias revolucionárias. Pensa-se nele como um alfabetizador - alguém que inventou um método de alfabetização de adultos que necessita poucos dias para funcionar, apoiado em esquemas de assimilação do grupo de educandos e se desenvolve a partir de pesquisa de palavras semanticamente impregnadas pela cultura do grupo.

Realmente, Freire é isso; e quando alguém conhece, ao menos este "ângulo" do ser multifacetado que nele se constitui, já se pode celebrar! Mas Freire não é só isso, e para por em prática seu método, é preciso conhecer muito bem suas teorias: o caráter revolucionário expresso em sua obra e que está quase todo contido em seu livro mais radical - Pedagogia do Oprimido. O método Paulo Freire não é nem um passe de mágica que se realiza a partir de um ato voluntário do educador e muito menos uma receita que se aplica a dada situação como uma espécie de tecnologia social. Esse método exige que o educador deixe de ser o opressor e liberte seus educandos para deixarem de ser oprimidos ${ }^{2}$. Isto não é fácil. A escola capitalista não se transforma em espaço de liberdade - contida que está por limites burocráticos e curriculares. É uma instituição controlada pelo Estado e hoje mais do que antes voltada ao mercado. Como introduzir uma prática libertadora em espaços ideologicamente projetados para a domesticação

\footnotetext{
${ }^{1}$ Cumpre reconhecer que o próprio Raymond Williams, pouco antes de morrer, se mostrou profundamente decepcionado com os rumos tomados pela Comprehensive School na Inglaterra (1986).

${ }^{2} \mathrm{Ou}$ seja, é preciso ter a humildade de reconhecer a cultura do outro (acolher o outro).
} 
das novas gerações? Nas creches construídas para os filhos da classe trabalhadora, crianças são enfileiradas e submetidas a tarefas impostas pelo sistema. Em espaços confinados, o que vemos aí, são pequenos "campos de concentração", nos quais as crianças permanecem presas praticamente o dia inteiro, para serem domesticadas.

Há escolinhas particulares, dirão alguns, com menos alunos e mais liberdade, que inclusive proclamam a adoção do método Paulo Freire como base da aprendizagem. Mas os métodos são apenas mais suaves, mais sutis, baseados no colorido e na fantasia, impostos à criança que ali permanece hipnotizada pela sedução da mercadoria. Freire é, em alguns casos, apenas a grife que atrai aos pais. Que prática libertadora pode ser aplicada à situação escolar aqui entendida?

No entanto, é importante ressaltar que a escola não é só isso. A escola é um espaço de contradições (WHITAKER, 1984) e mesmo crianças muito pequenas, em creches, apresentam atos de rebeldia que demonstram resistência à dominação - em atitudes que poderiam ser aproveitadas pelos educadores para um exercício de libertação. Mas isto exige uma postura dialógica para a qual a grande maioria não foi preparada - fruto que é de uma escola domesticadora, com suas estratégias de educação bancária e opressiva. A História da Educação e, principalmente, os resultados da educação escolar neste país mostram duas evidências desse tipo de educação, a saber:

1. Os alunos não aprendem verdadeiramente aquilo que lhes é dado em "depósitos" no cotidiano escolar, encarados que são como recipientes (FREIRE, 2013) e submetidos à Autoridade Pedagógica (BOURDIEU \& PASSERON, 1982) contra a qual, aliás, cada vez mais se rebelam a todo instante;

2. Um processo político de libertação relativa, promovido por um partido de esquerda no poder durante 14 anos - verdadeira Primavera Petista (ou política) - ainda não despertou estudantes para a sua defesa e foi dissolvido com relativa facilidade pelo poder econômico e financeiro das corporações internacionais petrolíferas ${ }^{3}$.

Lembremos em defesa dos jovens e adolescentes que houve ocupação de escolas por parte de estudantes do Ensino Médio e da Universidade e que estas ocupações venceram um poderoso governador no Estado de São Paulo. Mas o processo se desvaneceu e apenas serviu para mostrar o potencial de mudança da juventude, já diagnosticado por Mannheim nos anos

\footnotetext{
${ }^{3}$ É bem verdade que nossa soberania foi destruída com o apoio do judiciário e do congresso e o projeto de dissolução dessa soberania foi arquitetado por forças inexoráveis, mas não podemos nos esquecer dos quase 40 milhões de eleitores que votaram num projeto de governo conservador e reacionário.
} 
1940 e que a escola não consegue desencadear ${ }^{4}$. A realidade é mesmo paradoxal: uma escola domesticadora engendra comportamentos revolucionários? Talvez seja por conta deste paradoxo que a estrema direita teme um teórico amoroso e cristão que em 1964 teve que se asilar no exterior para não ser preso. E em 2019 tem sua memória desrespeitada no país que queria libertar.

Para compreender o medo que inspiram suas ideias humanizadoras, é preciso conhecer sua incrível trajetória. Vamos tentar reconstruí-la, enfatizando, não aqueles fatos e aspectos que a maioria dos estudiosos coloca em evidência, mas sim alguns pontos que definem, a nosso ver, mais dramaticamente os caminhos que o levaram a formular tão grandioso edifício teórico, a partir de suas experiências no país colonizado que se descolonizou sem descolonizar seu povo. Incrível, mas não inexplicável, que tudo que pensou, explicou, sugeriu, tenha sido elaborado observando a educação e seu potencial como prática libertadora.

\section{A influência feminina na vida de Paulo Freire}

Inúmeros pesquisadores realizaram excelentes biografias sobre Freire (por exemplo: BARRETO, V., 1998 e ARAÚJO FREIRE, A. M., 2005), por isso nos dispensamos de fazer uma cronologia da sua vida. O que nos chamou a atenção em sua trajetória foram determinadas pistas que indicam uma presença de capital cultural anterior ao período da pobreza e a influência poderosa das mulheres em sua vida.

Sua própria mãe tinha boa formação, uma vez que o alfabetizou. Sua irmã Stela fez Escola Normal, que era então um curso para moças da classe média, e a sua primeira esposa, Elza, foi professora. Além de Ana Maria que é pedagoga. Sem querer essencializar a ideia do "olhar feminino" sobre a visão de mundo e ciência desse intelectual, buscamos compreender quem influenciou Paulo a ver o mundo de um ângulo que não ressalta os valores da sociedade capitalista e que não se ajoelha ao lucro.

Araújo Freire (2005) descreve o "seu mais autêntico contexto de origem": uma família de classe média, com ethos altamente valorizador do conhecimento, que alfabetiza o menino Paulo aos 4 anos de idade, embaixo de uma mangueira ${ }^{5}$. Dessa forma procuramos evitar o equívoco que se comete a respeito de Freire que é pensar a sua origem como cheia de carências.

\footnotetext{
${ }^{4}$ Esta introdução já estava pronta quando se iniciaram manifestações estudantis em Maio de 2019 em diferentes universidades pelo país todo. A realidade é dinâmica, o que renova esperanças ou anuncia o desespero.

${ }^{5}$ É evidente que a sombra da mangueira não significava carência de espaço, mas apreço pela natureza. Vamos dar algumas pistas da classe social da família e seu capital cultural: a) a esplêndida carta que seu pai Temístocles escreve ao futuro sogro para pedir a mão de sua mãe Eltrudes em casamento; b) o livro do bebê de Paulo com a descrição da infância carregada de requinte e várias fotos; c) a família extensa de Paulo que vivia rodeado de adultos intelectualizados, alguns altamente politizados; d) as referências musicais em sua família, como a tia Lurdes que tocava piano e o pai que tocava violino. Para outras referências ver Araújo Freire (2005).
} 
Freire em "Cartas à Cristina" ao se referir à família, reflete sobre a sua condição de classe:

\begin{abstract}
Em nossa casa havia um piano alemão em que Lurdes, uma de nossas tias, tocava Chopin, Beethoven, Mozart. Bastava o piano para nos distinguir, como classe, de Dourado, de Reginaldo, de Baixa, de Toinho Morango, de Gerson Macaco, alguns amigos daquela época. O piano, em nossa casa, era como a gravata no pescoço de meu pai. Nem a casa se desfaz do piano, nem meu pai da gravata, apesar das dificuldades que tivemos. O piano e a gravata eram, no fundo, símbolos que nos ajudavam a nos manter na classe social a que pertencíamos. [...] Nem o piano era somente um instrumento para o deleite artístico de Lurdes, nem a gravata de meu pai era apenas uma exigência da moda masculina, pois que ambos, o deleite artístico e a moda, tinham a sua marca classista. Perdê-los poderia ter significado perder também a solidariedade dos membros da mesma classe e marchar de degrau em degrau, até o mocambo dos córregos ou dos morros de onde dificilmente poderíamos ter voltado. Preservá-los, por isso mesmo, foi algo necessário para que a família atravessasse a crise mantendo a sua posição de classe (FREIRE; 2003, pág. 46 - 47).
\end{abstract}

Segundo Ana Maria, "Paulo falava da dificuldade da família em aceitar a decadência de quem era de classe média, que vivia numa agradável casa com jardim de rosas e quintal cheio de pássaros e árvores frutíferas, em Recife, e tornar-se pobre numa muito pobre cidade do interior" (ARAÚJO FREIRE; 2005, 47).

A pobreza chegou mais tarde quando Paulo atingia 8 anos (com a crise de 1929), momento em que a família perde a casa com seu belo quintal e se vê obrigada a mudar para Jaboatão dos Guararapes. Junto com a crise, a perda do pai vai levá-los à fome.

$\mathrm{Na}$ cidade pobre do interior, Paulo participava também do mundo dos meninos e meninas dos córregos, dos mocambos, dos morros. Se auto-denominava o "menino conectivo" (BARRETO, 1998). Foi também em Jaboatão que Paulo "sentiu, aprendeu e viveu a alegria no jogar futebol e no nadar no rio Jaboatão vendo as mulheres de cócoras, lavando e batendo nas pedras as roupas que lavavam" (ARAÚJO FREIRE; 2005, 48). Alguns autores, no entanto, chamam a atenção para os aspectos positivos dessa fase da vida de Freire, pelo caráter criativo em sua infância, além do contato com outras classes sociais exploradas.

Segundo Araújo Freire (2005), foi conhecendo as contradições sociais que Freire forjouse na disciplina da esperança. Foi dona Tudinha, sua mãe, que peregrinou pelas escolas secundárias até que uma fornecesse o ensino gratuitamente ao menino. Ela conversou com o Dr. Aluízio, diretor do Colégio Oswaldo Cruz, já que Paulo havia finalizado o primário em Jaboatão e só poderia continuar a estudar o secundário se não tivesse que pagar mensalidade 6 .

\footnotetext{
${ }^{6}$ Como todos sabem, antes da lei no 5692/1971, a estrutura do sistema de ensino era baseada em curso obrigatório de apenas 4 anos, o antigo primário. O secundário, já era propedêutico, e preparava para continuidades elitizantes.
} 
Seu brilhantismo foi percebido logo, no colégio onde estudava, e no qual se tornou professor, ainda enquanto estava no secundário, dando aula no Curso de Admissão (ARAÚJO FREIRE; 2005, 54). Começa aí a carreira de nosso extraordinário educador.

Foi depois de graduado em Direito que Paulo conheceu Elza Maia Costa de Oliveira, uma professora de pré-escola que marcou a sua vida pessoal e profissional. Aos 23 anos de idade Freire se casa com Elza, com quem viveu 42 anos e teve 5 filhos. Embora tenha se formado advogado, Paulo teve apenas uma única experiência com esta profissão. Pouco tempo depois de deixar a advocacia, Freire passa a trabalhar no SESI (Serviço Social da Indústria). Os dez anos que passou nesta instituição foram decisivos para a sua formação como educador.

Entre os aspectos não enfatizados de sua trajetória é preciso ressaltar a importância das duas mulheres com quem foi casado. A relevância de Elza transparece em muitos momentos de sua biografia. Na obra "Pensando com Paulo Freire" (2012) se enfatiza uma passagem do pensador que mostra a importância da primeira esposa na sua percepção do outro. O próprio Paulo contava o episódio em suas palestras.

Numa ocasião teria sido convidado para falar sobre castigos violentos. Ao final de sua fala, um operário que participava do evento o questionou sobre as condições de conforto em sua casa. $\mathrm{O}$ mesmo afirmava que entre os trabalhadores era difícil manter a calma com os filhos após um dia extenuante de trabalho ao chegar numa casa pequena e cheia de crianças. Freire, após o evento, enquanto voltava de carro para casa, comenta com a esposa que talvez eles não o tivessem compreendido. A essa indagação, ela pergunta: “- Não terá sido você, Paulo, quem não os entendeu?”. E continuou: “- Creio que entenderam o fundamental de sua fala”. “- O discurso do operário foi claro sobre isto. Eles entenderam você, mas precisavam de que você os entendesse. Esta é a questão"7 . Em outra passagem da obra Conscientização, Freire (1979, pág. 15) diz:

\footnotetext{
À Elza, primeiro professora primária e, depois, diretora de escola, devo muito. [...] (pressente a necessidade da ajuda), me têm sempre sustentado nas mais problemáticas situações. Foi a partir do casamento que comecei a me preocupar sistematicamente com problemas educacionais.
}

Sobre a importância de Ana Maria, basta lembrar o trabalho verdadeiramente enciclopédico que a mesma realizou e que se constitui uma fonte inesgotável para a compreensão da sua obra Paulo Freire: uma história de vida.

Escolhemos, em nossa abordagem, chamar a atenção para detalhes da vida de Freire, que pareceram decisivos para a sua trajetória, mas é lógico que esse intelectual construiu a sua

\footnotetext{
${ }^{7}$ Uma das autoras deste artigo lembra-se de ter ouvido essa passagem em uma das palestras de Freire após seu retorno do exílio.
} 
obra a partir de diferentes estudos e reflexões, o que lhe permitiu elaborar uma teoria que o equipara aos grandes teóricos da opressão que viveram a descolonização da África e Ásia.

Freire tinha um "olhar feminino" para o mundo e para o fazer ciência e isso repercutiu em sua atuação profissional e elaboração teórica, pois nunca o vemos estimular uma postura agressiva e competitiva. Temos que recordar nesse ponto que para Capra (1982), a Nova Ciência deverá produzir uma nova cultura e um novo ser, o que exige a incorporação do "olhar feminino" sobre o mundo e as coisas.

Quando ressaltamos a presença do "olhar feminino" em Paulo Freire, não estamos querendo reforçar a dualidade e a dicotomia entre o gênero masculino e o feminino. Ao nos referirmos a esse olhar, demonstramos que é uma visão de mundo que dispensa o sucesso, a competitividade, a agressividade. A não agressividade é uma característica de seu pensamento, atitude de quem aprendeu a não estimular as relações de poder.

Se ele não era agressivo, como chegou à radicalidade de Pedagogia do Oprimido? Acreditamos que a virada da década 1960 para 1970 foi o momento ideal para se rebelar contra a opressão e a energia acumulada pela compressão vivida e que, no caso de Freire, essa rebeldia teve como válvula de escape as folhas em branco postas em sua mesa de trabalho. Isso porque a violência provocada pelo sistema carece de uma resposta. É provável que já como cidadão do mundo, Freire, exilado no Chile, conseguiu se libertar dos paradigmas do nacional desenvolvimentismo e deu uma grande resposta ao sistema com Pedagogia do Oprimido.

Ou seja, Freire sai do lugar de poder, dado pelo status de professor e estabelece uma relação horizontal entre educador-educando, o que nos leva ao princípio da dodiscência: ao fazer e ao ensinar nós aprendemos. Nesse sentido, as ideias freirianas se revelam estar em consonância com a Nova Ciência.

Sua trajetória oferece pistas tanto de sua forma de pensar, como da dificuldade de aplicação dos seus métodos. Numa sociedade cujas subjetividades são profundamente influenciadas pelo ponto de vista masculino e pela ânsia de ascensão social, como formar professores (as) que valorizem aspectos femininos da cultura e conhecimentos forjados na pobreza material dos "outros" (seus alunos)?

\section{Perseguições e neoconservadorismo}

A trajetória de Freire, principalmente após o exílio, tem repercussão internacional - o educador, citado e considerado em diferentes partes do mundo, com títulos de honoris causa em universidades de renome, torna-se um intelectual dos mais significativos na luta em favor 
dos oprimidos. Seu método e suas teorias são aplicados por movimentos revolucionários no período da descolonização, quando oprimidos se libertavam na África e na América Latina. Só não se podia aplicar suas ideias no país onde nasceu. Vamos refletir agora sobre os fatores condicionantes desse fenômeno.

Por que um pensador cristão, ligado à Igreja, amoroso, humanista, incomodou tanto as forças reacionárias que tomaram conta do Brasil, justamente nos anos 1960, quando a contestação era a tônica nos países capitalistas?

No livro já citado de Araújo Freire, é possível encontrar em muitas páginas, que reproduzem o capcioso e perverso interrogatório ao qual foi submetido imediatamente após o golpe, informações sobre as perseguições de ontem e que explicam as de hoje também. Vamos reproduzir aqui as primeiras conclusões do inquérito feito em Recife:

Paulo Reglus Neves Freire ${ }^{8}$ :

Autor de "suposto método" de alfabetização, onde dizia que alfabetizar é conscientizar e politizar.

Tentou ludibriar o governo com seu suposto método de alfabetização, procurando vende-lo em diversas situações.

Nenhum motivo tem a Pátria para agradecer os trabalhos de Paulo Freire e, ao contrário, a Pátria traída o procura, pelos atuais responsáveis pelo seu destino, para que lhe pague os danos causados.

É um cripto comunista encapuçado (sic.) sob a forma de alfabetizador (...) (ARAÚJO FREIRE; 2005, 199).

Apenas esse pequeno trecho dá ideia da perversidade e da violência daqueles que se encarregaram da tarefa de caluniá-lo. POR QUÊ? É importante saber o porquê, para compreender o fenômeno que se repete, em 2019, com a extrema direita no poder no Brasil. Freire está morto, mas seu pensamento vive e cada vez mais em diferentes países.

A onda neoconservadora vem nos assombrando desde o início do século XXI e não por acaso vimos nas manifestações conservadoras de 2015 lideradas pelo MBL - Movimento Brasil Livre - cartazes que diziam "Abaixo Paulo Freire" ou "Menos Doutrina Marxista". Esses movimentos não ignoram a realidade, nem são movidos apenas por crenças ou pela falta de conhecimento sobre as teses de Paulo Freire e os problemas da sociedade brasileira.

Toda a energia daquelas manifestações foi também canalizada pelas forças econômicas internacionais para uma virada do jogo político. As ondas conservadoras podem, portanto, encobrir avanços de um processo cultural e não é por acaso que os neoconservadores atacam a educação e a cultura.

${ }^{8}$ Parte do relatório do inquérito policial militar do tenente coronel Hélio Ibiapina Lima, Recife/PE, 18 de outubro de 1964. 
$\mathrm{O}$ ataque direto do atual governo conservador no Brasil está direcionado às conquistas sociais, educacionais e culturais que são reflexo de políticas públicas criadas ao longo de 14 anos de governos petistas. Todo esse processo de democratização do Estado brasileiro tem como marco a constituição de 1988, mas os avanços nas questões indígenas, dos quilombolas, as questões étnico-raciais, das mulheres e das populações LGBTTTI são derivados de muita luta e resistência, além de uma efervescência dos movimentos sociais.

Na atualidade, com o golpe de Estado em 2016 que depôs o governo de Dilma Rousseff e a eleição de Bolsonaro em 2018, as elites nacionais e internacionais pretendem negar a voz aos grupos que não compactuam com o sistema conservador, reprodutor das desigualdades o qual estimula a dominação e a violência no Brasil, pois a soberania desses grupos sociais pode contrariar interesses.

Hoje em dia, muito mais que na década de 1960, as vozes e os discursos contraideológicos se encontram melhor elaborados, os movimentos sociais mais organizados, tal como observamos os coletivos de povos e nações indígenas, negras e negros, mulheres, LGBTTTI's. A ideologia tenta controlar o desenvolvimento da cultura, mas a dominação, ao mesmo tempo, também produz a contra-ideologia naqueles submetidos à opressão.

A onda neoconservadora quer calar as nações indígenas, os movimentos negro, feministas, LGBTTTI's e outros povos tradicionais, negar o valor que têm seus saberes, suas histórias e combater as contra-ideologias criadas por esses grupos.

Pensar o pensamento de maneira crítica geralmente tira as pessoas de suas situações de conforto. As explicações pouco fundamentadas não causam mal-estar, não desnaturalizam os processos sociais, não nos tiram de um lugar de segurança e, portanto, corroboram para a manutenção do status quo. Por isso é possível compreender que o pensamento crítico também cria uma sensação de desestabilidade.

Esse era o caso do método de alfabetização de Paulo Freire, o qual tirava os mais pobres do lugar de conforto que a alienação provocava. Talvez seja isso que o governo Bolsonaro tenta evitar para que não continue acontecendo no Brasil, silenciando essas vozes, querendo que a escola e a educação seja aquela mesma que Bourdieu \& Passeron (1982) denunciavam na década de 1970.

Em contrapartida, os movimentos sociais lutam por aquela escola que Freire anuncia. Vejam a dialética! É um pressuposto da luta dos movimentos sociais criticar a lógica da educação reprodutivista. Por exemplo, o movimento negro propõe uma escola com uma educação antirracista, os movimentos indígenas propõem que a educação indígena sirva em seus projetos políticos, culturais e sociais, o movimento feminista luta por uma educação que 
conteste o machismo. Todas essas pedagogias, portanto, são críticas à lógica reprodutivista da educação escolar,

O silenciamento e a repressão nos levam também à obra Pedagogia do Oprimido de Freire, pois como bem nos esclarece o professor Ernani Maria Fiori a proposta dialógica e dialética de educação dele tem como principal objetivo fazer o oprimido "aprender a dizer a sua palavra”. Para Freire, que escreveu essa obra no Chile, observando a repressão na América Latina e o processo de descolonização na África, é preciso criar uma educação como prática de liberdade, substituindo a educação bancária ou reprodutora que prevalece na escola capitalista e que garante a opressão. Nesse caso especial, a teoria freiriana é altamente ameaçadora aos opressores. Quem é esse intelectual que propõe uma relação de igualdade entre um educador que também se educa e um educando que também ensina? Não por acaso, essa obra foi proibida no Brasil na época da ditadura civil-militar. E está novamente ameaçada.

Isso fica mais claro quando compreendemos que na episteme de Freire é fundamental ler primeiro o mundo e depois ler a palavra. E mais do que ler o mundo e a palavra, aprende-se também a ler a opressão na qual as classes oprimidas estão engendradas enquanto peças fundamentais para o processo de dominação das classes opressoras. É por isso que as ideias e a pedagogia freiriana são classificadas pela ultradireita como perigosas e subversivas.

Em 1963, nos 45 dias da experiência de Angicos, vê-se, por exemplo, um cenário de pobreza e analfabetismo no sertão do Rio Grande do Norte. Assim como Paulo Freire é "perseguido" em 2019 pela ultradireita, em 1963 também o foi, após essas 40 horas da experiência, momento no qual o presidente João Goulart se deslocou para essa cidade para participar da cerimônia da entrega dos certificados que atestavam a alfabetização de 300 trabalhadores.

Castelo Branco, que participava da comitiva de Jango, indagou Freire sobre o poder de transformação de seu método de alfabetização. Segundo Guerra (2013), à pergunta do marechal (que em 1963 era chefe do Estado Maior do Exército), Freire respondeu que era um método bastante revolucionário. Para complementar a conversa, Guerra nos lembra de que o marechal concluía e dizia a Paulo que se tratava de um método subversivo. Podemos sentir nesse episódio o caráter ameaçador que preparava o golpe para o ano seguinte. 


\section{Educação escolar: reprodução ou libertação?}

Na medida em que foi se desvanecendo a ditadura no Brasil, os sociólogos começaram a observar que as crianças ficavam apenas três horas por dia e um pouco mais de 2 ou 3 anos na escola, o que entrava em contradição com as teorias da reprodução. Ao mesmo tempo em que havia uma pressão social por parte das classes populares para o acesso à escola, para muitos pedagogos essa instituição se configurava num vilão das desigualdades sociais. É nesse momento que se buscam outras teorias para nossos problemas educacionais e a intelectualidade brasileira passa a retomar Freire que estava exilado.

No método Paulo Freire o processo ensino-aprendizagem parte do contexto cultural do educando porque a leitura do mundo que é necessária realizar é decisiva enquanto instrumento para desvendar o processo ideológico. A nosso ver, esse momento teórico-metodológico da proposta de Freire é o mais difícil de ser aplicado. Na escola capitalista, seria possível aos professores, controlados pela ideologia, fazer a leitura do mundo?

Vemos, ao longo da história, muitas deformações do método de alfabetização de Paulo Freire, que inovou no processo ensino-aprendizagem ao desinfantilizar a educação de adultos. O MOBRAL - Movimento Brasileiro de Alfabetização -, inaugurado na ditadura e que durou até 1985, por exemplo, dizia aplicar a metodologia de Freire, entretanto sabe-se que as palavras geradoras não eram extraídas a partir da investigação do universo vocabular no seio da comunidade alvo do processo de alfabetização, mas enviadas pelo MEC, por Brasília - DF, sem que as mesmas tivessem significado e sentido para a alfabetização dos educandos. Essa é uma prática tecnicista que contradiz o que propõe o método Paulo Freire e acaba por interromper o diálogo com os educandos e suas realidades.

A leitura e a escrita, em Freire, devem ser significativas para aqueles que se alfabetizam, ou seja, devem estar contextualizadas em processos históricos e sociais. O melhor exemplo é o das campanhas de alfabetização em massa na América Latina, que atenderam 180 mil pessoas na Nicarágua no final da década de 1970. Fica muito claro que os próprios revolucionários implantaram processos de ensino-aprendizagem sem que houvessem estabelecido formalmente um projeto político pedagógico, apesar de baseados no método Paulo Freire. Segundo dados oficiais do governo desse país, em cinco meses, a taxa de analfabetismo teria diminuído em 12,9\% (FRAGA; 2010, 197).

Freire é combatido também porque a luta política produz conhecimento e aprendizado, já que é possível demonstrar que a educação popular auxilia os grupos em seus projetos políticos e sociais. O que assustou mesmo antes de 1964 e agora em 2019? O fato de que o 
educador, numa abordagem freiriana, deve levar em consideração o educando, pois se não há submissão entre educador-educando, o educando não vai se submeter à sociedade. É o medo, portanto, da autonomia e da liberdade que assustou antes e assusta agora.

O que assusta no educador freiriano é que ele tem que levar em conta o educando abrindo o campo educacional para a perspectiva inclusiva e para a autonomia do conhecimento que não se submete à hierarquia previamente dada por "quem sabe mais". E como o educando na perspectiva freiriana não pode se submeter à relação hierarquizada professor-aluno, o mesmo não irá se submeter à hierarquia imposta pela sociedade em outras instâncias. O medo das ideias freirianas se explicita quando os conservadores e reacionários compreendem que é possível realizar uma educação que não domesticadora.

Esse medo das ideias de Freire está presente tanto naqueles à direita do espectro político, quanto à esquerda, pois é o sentimento que sobressai frente à autonomia do conhecimento e à liberdade. Isso se coloca como questão importante porque se observa que a própria esquerda ortodoxa tem receio de se submeter às ideias do autor de Pedagogia do Oprimido.

$\mathrm{O}$ ataque atual aos professores e à educação, o livro-didático que passa por revista para que temas e atitudes politicamente corretas não sejam debatidos, são exemplos do que a educação escolar em sua perspectiva crítica pode sofrer com a chegada da ultradireita ao poder. Quais os efeitos dos discursos presentes na onda neoconservadora para a educação escolar e aos professores? Há hoje muitos sujeitos na educação escolar que têm medo de problematizar e não querem mais falar de temas vigiados pelas patrulhas neoconservadoras com receio de correrem riscos ou serem punidos.

Em Pedagogia do Oprimido Freire é radical porque vai à raiz do problema de uma sociedade como a nossa, que é a opressão, estabelecendo um diálogo com outros autores que estudaram o fenômeno. Segundo ele, somente o oprimido pode se libertar do opressor que existe dentro de si. Esse pressuposto é criado a partir de um diálogo entre Freire e o filósofo, psiquiatra e escritor martinicano de ascendência africana e francesa, Fanon, autor da célebre obra $O s$ condenados da Terra.

Na perspectiva de Freire (2013), quem inaugura o ódio é o opressor. Quem nega aos homens a humanidade que carregamos não são os que tiveram a humanidade negada (os oprimidos), mas os que a negaram primeiro (os opressores). Freire se preocupa em compreender como os processos de dominação se reproduzem no sistema e é por isso que inaugura um diálogo transatlântico sobre a opressão com os teóricos africanos e africanistas que estudaram o colonialismo e o pós-colonialismo. 
Em obras como $O$ retrato do colonizado precedido pelo retrato do colonizador de Albert Memmi ou em Os condenados da Terra de Franz Fanon, além de Pedagogia do Oprimido de Freire, é fundamental que o oprimido consiga se libertar do opressor que tem dentro de si para que ele possa encontrar a sua identidade e entender quem ele é. E isso é fundamental para que o oprimido não se aprisione ou se condene enquanto um "ser menos" em seu próprio território. Tal discussão é importante na atualidade para se entender quem são esses, no caso brasileiro, que estão submissos à opressão. Mas também podemos compreender quem também são esses que não optaram pela liberdade, ou seja, quem são os que seguem o $38^{\circ}$ presidente brasileiro como se fosse um mito salvador do Brasil do "comunismo"? O entendimento desse processo pode nos desvelar quem dá energia a essa onda neoconservadora. Para nós pode ser que sejam aqueles para os quais os laços sociais e culturais se romperam ou se esfacelaram, os mesmos que submetidos aos ditames homogeneizantes da economia global perderam os dados de suas culturas, o que dificultou a formação de suas identidades em meio ao alvoroço globalizante, de modo que os mesmos não se enxergassem como atores do processo histórico em andamento. Considera-se que seja esse um fator importante para a explicação de como esses indivíduos se tornaram massa de manobra político-econômica, pois se um sujeito não se sustenta numa estrutura social e cultural fica mais fácil de ser manipulado e dominado. O que ocorre aí, também, é a perda de fé na democracia representativa, fenômeno que vem acontecendo em diversos países.

Isso tudo não significa que a democracia deva ser substituída pelo fascismo, tal como proposto pela extrema direita. Há outras propostas: se a democracia inventada pela burguesia fenece, outras formas de democracia são possíveis e já anunciadas pelos movimentos da economia solidária que criam a democracia participativa, ou formas de socialismo democrático, tal como anunciado pelos movimentos sociais nos quais ecoam as propostas de Freire.

Assim como há possibilidades nos campos social e econômico, há também possibilidades na prática pedagógica. Freire apresenta a educação em sua dualidade: existe a educação bancária, domesticadora e existe a educação como prática de liberdade. Como a educação apresenta essa dualidade, ela será aplicada como técnica social numa ou noutra perspectiva, conforme o momento político e a diretriz definida nele.

Por que Freire acreditava na conscientização nos anos 1950 e 1960 ? E porque que depois do golpe de 1964 o autor mudou seu discurso e passou a ter ideias que iam na raiz do problema educacional e com estreita relação com os estudos sobre a opressão decorrentes das independências africanas? Vamos discutir essa problemática na conclusão deste artigo quando abordarmos os diferentes momentos do pensamento desse intelectual. 
Apesar de Freire ser um pensador cristão, foi um dos primeiros a ser perseguido no golpe de 1964, preso durante mais de 70 dias. Quando solto, atravessou a fronteira para a Bolívia, porque sua situação no Brasil oferecia perigo.

Nos anos 1970, surgiu um discurso pedagógico para o qual a educação era responsável pela manutenção das desigualdades sociais, discurso esse fortemente influenciado pelas teorias da reprodução. No entanto, o mesmo momento histórico nos coloca umas boas questões: se a escola era autoritária, porque os pobres queriam tanto essa instituição a serviço de seus filhos? Porque o poder autoritário de ontem e hoje também demonstra tanto medo do que é dito na escola e do processo de escolarização das massas? A escola, numa perspectiva otimista, tem muita potencialidade e pode criar possibilidades de mudanças sociais. Talvez sejam essas as características da proposta freiriana que causam temor.

Vamos tentar compreender a dificuldade em se propor o método de Freire na educação escolar brasileira. Para Celso Beisiegel (1984) a escola pública no Brasil deveria assumir Freire e a educação popular, o que nunca ocorreu. Em sua visão, não adianta que apenas os movimentos sociais manuseiem essa tecnologia social, uma vez que esses estariam atuando de forma pontual. Para o autor, a incorporação da educação popular pela educação escolar seria a única proposta possível para essa instituição estatal romper com a lógica reprodutivista do sistema e se tornar uma escola freiriana. Apesar de a escola pública ser reivindicação do povo, ela nunca se consolidou enquanto uma proposta de educação popular.

A começar pelo currículo e a sua estrutura hierárquica, a escola pública se mantém extremamente eurocêntrica, reproduzindo o arbitrário cultural dominante. Não por acaso, a primeira preocupação de Freire, quando assumiu a Secretaria Municipal de Educação da cidade de São Paulo, foi a reforma curricular. A segunda se referia à organização dos conselhos escolares a fim de promover a participação da sociedade no projeto eco-político-pedagógico. Por mais que os teóricos tenham avançado sobre essa questão, a educação escolar, ainda hoje, continua sob a tutela do Estado, mesmo que o partido no governo seja mais aberto à participação política da sociedade. Ou seja, quando se trata da educação escolar, o Estado mantém seu controle e por mais que se tenham criado estratégias de participação como os PPP's, esses documentos continuam "uma ficção burocrática", geralmente criada sem a participação da comunidade escolar, o que deveria ser um pressuposto. A escola nem tem a autonomia, nem conta com a participação dos pais, que raramente são convocados.

Além disso, não é evidente que o bom funcionamento da escola derive de um bom projeto político pedagógico, pois se nos basearmos na educação problematizadora de Freire, o ato pedagógico se inicia com o educador aprendendo com os educandos. Dessa forma, o 
professor é levado a aprender o que os alunos têm para ensinar. E, por isso, nos fica uma questão: como articular esse pressuposto da dialogicidade à proposta de um PPP? Parece-nos que, mantendo-se a estrutura da educação escolar como a conhecemos, será difícil para as comunidades escolares implantarem as práticas freirianas.

Para se aplicar o método Paulo Freire é necessário o desenvolvimento de pesquisas, para as quais muitas vezes o nosso professorado não está preparado, já que essa formação científica é ainda restrita a uma pequena parcela dos estudantes universitários brasileiros. Vale destacar que nas obras organizadas por Brandão (1981), as experiências de alfabetização de Freire são de rigorosa pesquisa crítica e interventiva com relação à realidade que pretende estudar.

A ideologia, ou seja, o pensamento dominante constitui um obstáculo à introdução das ideias freirianas na educação escolar brasileira. Porém, enquanto vivíamos sob os governos petistas, observávamos com mais facilidade as possibilidades de aplicação dos pressupostos da educação popular e das ideias de Freire. Um exemplo da importância desses pressupostos e de como eles não ficaram esquecidos no campo educacional, pelo menos para uma parcela dos estudiosos, pode ser ilustrado pelo documento que expressa o Marco de Referência da Educação Popular para as Políticas Públicas de 2014. Daí que se pode falar que ao longo da primavera petista, Freire foi constantemente invocado em programas federais e nas propostas de educação do MST.

Cumpre lembrar que houve um processo de esquecimento de suas ideias nas universidades brasileiras, ora por falta de reconhecimento, ora pelo fato de não estar presente enquanto referência bibliográfica nos cursos de licenciatura e pedagogia no Brasil. Se, por um lado, Freire passa por um processo de esquecimento por parte de alguns setores do campo acadêmico, por outro é muito debatido em grupos de pesquisa e por alguns intelectuais.

Na universidade brasileira há exemplos concretos de intelectuais que contribuem para o apagamento do pensamento de Freire no campo acadêmico. O próprio MST tem utilizado em suas propostas pedagógicas outros teóricos que estão afastados de nossa realidade social, como é o caso do uso das ideias do russo Moisey M. Pistrak. Por isso cabe ainda perguntar: Quem tem medo de Paulo Freire? 


\section{Considerações finais}

Recordemos a evolução do pensamento crítico em Freire: nos anos 1950 e 1960, seus escritos enfatizam a necessidade de conscientização, tal como se observa na obra Educação como Prática da Liberdade (1967), inspirada por filósofos liberais, como Corbisier no Brasil e Dewey no E.U.A., que abordavam a relação entre educação e desenvolvimento. No Brasil, é o momento do nacional desenvolvimentismo, quando se apostava idealisticamente na possibilidade da nação se desenvolver com autonomia.

Freire propunha conscientização por meio da educação, uma revolução do pensamento. O autor avançará muito ao perceber que pensar conscientização sem luta resulta idealismo. Foi algo que empolgou o autor inicialmente porque era uma das discussões dos filósofos da época no Brasil, tais como Álvaro Vieira Pinto e Guerreiro Ramos. A sua noção ingênua de consciência será criticada posteriormente em Pedagogia do Oprimido. Lucien Goldmann, filósofo francês, é uma das influências marxistas que o ajudam a compreender que a visão de mundo é uma expressão cultural da representação do "máximo de consciência possível" de um grupo social. A consciência é permitida ou está contida no próprio sistema. Mas é preciso romper com os limites estabelecidos pelo sistema que impedem a compreensão do real.

Apesar de Gadotti nos ensinar que a filosofia da educação de nosso ilustre intelectual está baseada em Dewey, Snyders e Ausubel ${ }^{9}$, é surpreendente que essa base filosófica tenha sido radicalizada no pensamento de Freire a ponto de fazê-lo chegar à Pedagogia do Oprimido. Isso confirma nossa argumentação de que seu pensamento vai passando por uma crítica à noção romântica de conscientização, chegando aos teóricos da opressão: Fanon e Memmi.

Freire aproveitou dos pedagogos liberais a ideia de uma educação centrada no educando e na sua experiência, de modo a criar seu próprio método ativo de ensino-aprendizagem, fugindo de uma prática bancária de educação. Percebeu então que era preciso compreender a dominação do opressor. Além da experiência vivida, era importante dar sentido ao processo ensino-aprendizagem o que só se faria se pudesse transformar a realidade em que vivia os oprimidos.

Uma característica marcante do pensamento social a partir dos anos 1960 foi a denúncia das opressões: de classe, de gênero, étnico-racial, entre outras, momento do surgimento dos movimentos de contracultura, tal como os eventos de maio de 1968. Freire foi um dos intelectuais que se engajaram no Movimento de Cultura Popular de Pernambuco (MCP), uma vez que o prefeito da cidade de Recife na época, Miguel Arraes, havia se interessado em ampliar

\footnotetext{
${ }^{9}$ Em aula ministrada por Moacir Gadotti no curso “A Escola dos Meus Sonhos” no Instituto Paulo Freire em 2018.
} 
os projetos educativos de crianças e adultos nas amplas áreas de pobreza da capital pernambucana.

Os anos de 1970 podem ser considerados os de sua radicalização, marcada pela Pedagogia do Oprimido (publicada pela primeira vez em 1968) e pela influência da descolonização e dos teóricos da opressão. Fase bastante discutida neste artigo quando abordamos as perseguições e o neoconservadorismo.

A década de 1980, quando se prepara para a redemocratização do Brasil, refere-se a um período de esperança, certamente inspirado no processo político da constituinte e os avanços propostos pela Constituição Federal de 1988. Não podemos esquecer que Freire foi nomeado Secretário Municipal de Educação da cidade de São Paulo em 1989, no governo petista de Erundina. A obra de referência para o período é Pedagogia da Esperança (1992).

Haveria ainda outro momento de evolução nesse pensamento? Seria a década de 1990 e a obra Pedagogia da Autonomia (1996) que o inauguraria? É o momento do balanço de Freire sobre a democracia no Brasil, o que nos leva às discussões sobre o neoliberalismo, ao processo ideológico contundente na sociedade brasileira que impede os avanços das lutas sociais, à reflexão sobre a autoridade, o autoritarismo e a autonomia. Esses momentos do pensamento freiriano nos apontam para a relação entre as ideias pedagógicas e o processo político. Teorias sociológicas sobre a função da Educação Escolar - bem como pesquisas que as comprovam ou que são realizadas com seus pressupostos -, são aceitas e ganham força na medida em que correspondem ao momento político vivido pelo sistema, ou por críticas a esse sistema elaboradas, ou pela facilidade em explicar as atitudes dos principais atores sociais envolvidos.

O melhor exemplo é o das teorias da reprodução que empolgaram os pedagogos brasileiros nos anos 1970 porque denunciavam a escola capitalista como reprodutora das desigualdades sociais (BOURDIEU \& PASSERON, 1982). Naqueles anos, foi a "grande ideia" (como diria Geertz, 1989) através da qual os pedagogos pensaram ser explicativa para toda a realidade educacional do país. Afinal, vivíamos a ditadura e com a Lei 5692/1971 perdíamos História e Geografia como disciplinas do núcleo comum, que se organizavam em área de ensino como Estudos Sociais, e encarávamos disciplinas abertamente doutrinárias obrigatórias como Educação Moral e Cívica e OSPB - além de EPB (esta no nível da Universidade).

A relação entre ideias pedagógicas e o momento político de uma sociedade pode explicar o porquê do atual governo brasileiro, conservador e reacionário, desencadear a cruzada contra o marxismo e o pensamento de Freire. Tais matrizes de pensamento, apesar do contexto de surgimento bastante distante no tempo, além de fatores e influências distintas, estão orientadas para uma práxis que busca transformar tanto as relações sociais, quanto as relações 
pedagógicas. Nesse sentido, a proposta para a educação desse atual governo visa inibir práticas pedagógicas para a autonomia e liberdade.

No entanto, pesquisas sociológicas que se aprofundaram em estudos de caso sobre escolas específicas ou situações de sala de aula e, principalmente, nas áreas rurais (o MST, por exemplo) mostram o sucesso da adoção das ideias de Freire, principalmente por influência e empenho dos movimentos sociais. Enfatizamos que são experiências pontuais. Na realidade, a escola brasileira - seja pública ou privada - em que pese o louvável esforço de muitos educadores conscientes e/ou politizados, não está preparada para acolher, com hospitalidade, os modos de vida que caracterizam os arbitrários culturais dos dominados. Conforme destacado por Whitaker (1984) a escola brasileira sugere, por seus currículos e práticas da Autoridade Pedagógica, ser urbanocêntrica, sociocêntrica e preconceituosa. Caberia nela um professor que aprende com seus alunos e os acolhe com suas formas culturais para nelas construir os alicerces do "edifício" que compreende o arbitrário cultural dominante? Devemos lembrar que em Simpósio realizado em Berlim, no final dos anos 1990, o pensamento de Freire foi colocado como de fundamental importância. Um dos textos apresentados levava no título a expressão "o contraponto da esperança" (WHITAKER, 2000). Observado pelo ângulo da esperança e da reverência que suas ideias despertam, é possível pensar que tais obstáculos podem um dia ser superados e que teremos no país a escola sonhada pelo patrono da educação brasileira.

\section{Referências}

ARAÚJO FREIRE, A. M. (2005) Paulo Freire: uma história de vida. Indaiatuba - SP: Villa das Letras.

BARRETO, V. (1998) Paulo Freire para Educadores. São Paulo: Arte \& Ciência.

BEISIGEL, C. (1984) Ensino Público e Educação Popular. In: Paiva, V. (org.) Perspectivas e dilemas da educação popular. Rio de Janeiro: Ed. Graal.

BOURDIEU, P. \& PASERRON, J. C. (1982) A Reprodução: elementos para uma teoria do sistema de ensino. Rio de Janeiro: Francisco Alves.

BRANDÃO, C. (1981) Pesquisa Participante. São Paulo: Ed. Brasiliense.

CAPRA, F. (1982) O Ponto de Mutação. São Paulo: Cutrix.

FAGUNDES, R. \& BARBOSA, W. (2019) Por que o sistema educacional brasileiro nunca adotou Paulo Freire na prática? Le Monde Diplomatique - Brasil, nº 138, jan.

FRAGA, G. (2010) “A Nicarágua sandinista: guerrilha e educação” Revista História: Debates e Tendências - v. 10, n. 1, jan./jun. (p. 189-203). 
FREIRE, P. (1979) Conscientização. Teoria e prática da libertação: uma introdução ao pensamento de Paulo Freire. São Paulo: Cortez \& Moraes.

FREIRE, P. (2013) Pedagogia do Oprimido. 54ª ed. rev. e atua. Rio de Janeiro: Paz e Terra.

FREIRE, P. (2003) Cartas à Cristina: reflexões sobre a minha vida e a minha práxis. ARAÚJO FREIRE, A. M. (org.) São Paulo: Editora Unesp.

GEERTZ, C. (1989) A Interpretação das Culturas. Rio de Janeiro: LTC.

GUERRA, M. (2013) Sobre as 40 horas de Angicos. Em Aberto. vol. 26, n90, pág. 21-44. $\mathrm{jul} / \mathrm{dez}$.

SOUZA, Ana I. (2012) Pensando com Paulo Freire. Guararema - SP: Escola Nacional Florestan Fernandes.

WILLIAMS, R. (1986) The uses of Cultural Theory. In: New Left Review. ${ }^{\circ} 158$.

WHITAKER, D. C. A. (2000) Brasilien, Land der Zukunft? Die Projektionen Stefan Zweigs und Paulo Freire: der Kontrapunkt der Hoffnung. In: CHIAPPINI, L. \& ZILLY, B. (Hrsg.) Brasilien, Land der Vergangenheit? Frankfurt am Main: TFM.

WHITAKER, D. C. A. (1984) Ideologia e práticas culturais: o controle ideológico dos trabalhadores da cana. São Paulo, USP, FFLCH. 